\title{
Neuropeptide Y Selectively Inhibits Slow Synaptic Potentials in Rat Dorsal Raphe Nucleus in vitro by a Presynaptic Action
}

\author{
Samuel B. Kombian and William F. Colmers \\ Department of Pharmacology, The University of Alberta, Edmonton, Alberta, Canada T6G 2H7
}

\begin{abstract}
Neuropeptide Y (NPY) has been shown to modulate synaptic transmission in both peripheral and central tissues via both pre- and postsynaptic mechanisms. In this study, we examined the effect of NPY and its analog, peptide YY (PYY), on slow synaptic potentials in the dorsal raphe nucleus in vitro using intracellular recording and single-microelectrode voltage-clamp techniques. NPY and PYY inhibited both the slow 5-HT ${ }_{1 A}$ receptor-mediated IPSP and the $\alpha_{1}$-adrenoceptor-mediated slow EPSP while not affecting the fast, amino acid-mediated synaptic responses. PYY also inhibited pharmacologically isolated slow synaptic responses. NPY/PYY appear to mediate the observed inhibitions via a presynaptic mechanism, as the postsynaptic conductances mediated by activation of 5-HT $1 \mathrm{~A}$ receptors or $\alpha_{1}$-adrenoceptors were unaffected by the peptides. NPY/PYY act via a different mechanism than presynaptic 5-HT 18 receptors. NPY/PYY probably act via presynaptic $Y_{2}$ receptors, as the C-terminal fragment NPY 13-36 and the $Y_{2}$-selective agonist C2-NPY are effective. Since NPY and its receptors are present in the dorsal raphe nucleus, this peptide may act as an endogenous modulator of the state of activity of neurons in this region and may thus have a role in the modulation of neuronal output from this nucleus.
\end{abstract}

Ncuropeptide Y (NPY) has becn shown to have several neuromodulatory actions at pre- and postsynaptic sites in a number of tissues (Pernow et al., 1986; see other references below). In the rat hippocampus in vitro, NPY inhibits the fast (glutamatergic) synaptic potentials evoked in CA1 pyramidal neurons by stimulation of stratum radiatum. This action appears to be purely presynaptic in nature, as no evidence for postsynaptic actions of the peptide could be seen (Colmers et al., 1987, 1988). At sympathetic neuroeffector junctions, NPY inhibits release of noradrenaline (NA), and of itself, from presynaptic sympathetic terminals (Lundberg and Tatemoto, 1982; Lundberg and Stjärne, 1984; Lundberg et al., 1984; Lundberg and Hökfelt, 1986; Wahlestedt et al., 1990). Here, however, it also has direct and indirect postsynaptic actions; high concentrations of NPY directly cause

Received July 1, 1991; revised Sept. 25, 1991; accepted Oct. 23, 1991.

We are grateful to Dr. Alain Fournier of the INRS Santé, Pointe-Claire, Quebéc, for his generous gifts of PYY and NPY 13-36; to Dr. John Krstenansky (Merrell Dow Research Institute, Cincinnati, $\mathrm{OH}$ ) for his generous gift of C2-NPY; and to Sandoz Canada Ltd. for the gift of cyanopindolol. We thank Dr. J. T. Williams for helpful discussions throughout the course of the experiments. This work was supported by the Medical Research Council of Canada. W.F.C. is an Alberta Heritage for Medical Research Scholar; S.B.K. is a recipient of AHFMR and MRC (Canada) studentships.

Correspondence should be addressed to Dr. William F. Colmers, Department of Pharmacology, University of Alberta, Edmonton, Alberta, Canada T6G $2 \mathrm{H} 7$.

Copyright (c) 1992 Society for Neuroscience $0270-6474 / 92 / 121086-08 \$ 05.00 / 0$ a contraction of smooth muscle, while subthreshold concentrations of NPY enhance contractions caused by NA or other drugs (Ekblad et al., 1984; Wahlestedt and Håkanson, 1987). In the noradrenergic neurons of the brainstem nucleus locus coeruleus, some of which contain NPY (de Quidt and Emson, 1986), NPY appears to potentiate postsynaptic responses to $\alpha_{2}$-adrenoceptor activation; it is not known whether there are any effects on synaptic potentials evoked in this nucleus (Illes and Regenold, 1990). NPY's actions therefore vary with the system, presumably to elicit an appropriate, coordinated response to the higher levels of stimulation thought to cause preferential release of peptides (Bartfai et al., 1988).

The dorsal raphe (DR) nucleus is a brainstem nucleus composed mainly of 5-HT-secreting neurons that project rostrally to supply the serotonergic innervation of the forebrain (Andén et al., 1966; Azmitia and Segal, 1978; Fuxe and Jonsson, 1984; Mulligan and Tork, 1987, 1988; Aitken and Tork, 1988). These cells receive a variety of synaptic inputs, including fast responses mediated by the amino acids glutamate and GABA (Kalen et al., 1985, 1986; Pan and Williams, 1989a), and slower potentials mediated by 5-HT (Chazal and Rahlston, 1987; Williams et al., 1988) and NA (Aghajanian and Wang, 1977; Yoshimura et al., 1985). The pharmacology of these synaptic responses has been well characterized (Baraban and Aghajanian, 1980; Yoshimura and Higashi, 1985; Yoshimura et al., 1985; Williams et al., 1988; Pan and Williams, 1989a,b; Bobker and Williams, 1990). In addition, DR neurons are relatively compact electrically, permitting acceptable single-electrode voltage clamp of slow membrane conductances with conventional sharp electrodes. NPY is present in moderately high concentrations in DR (O'Donoghue et al., 1985), and NPY binding sites are concentrated there (Saria et al., 1985; Martel et al., 1990). The DR is therefore a good system in which to test the hypothesis that NPY acts at presynaptic sites to regulate synaptic transmission. The results indicate that NPY and related peptides selectively inhibit slow synaptic responses mediated by 5-HT and NA, by an action at a presynaptic site, while not affecting the rapid synaptic responses mediated by amino acid release. The peptide could, by its combined presynaptic actions, induce a change in state of the DR neurons similar to that induced in hippocampal pyramidal neurons by the postsynaptic action of N $\Lambda$.

\section{Materials and Methods}

In vitro slice preparation. Methods used were essentially similar to those reported earlier (Williams et al., 1988). Briefly, male Sprague-Dawley rats $(200-350 \mathrm{gm})$ were lightly anesthetized with halothane and killcd by a heavy blow to the spinal cord. The brain was then quickly removed and placed in ice-cold, carbogenated $\left(95 \% \mathrm{O}_{2}, 5 \% \mathrm{CO}_{2}\right)$, artificial cerebrospinal fluid (ACSF; pH 7.35). Coronal sections (350 $\mu \mathrm{m}$ thick) were then cut with a vibratome from a block of tissue containing caudal 
regions of the DR nucleus in cold $\left(4^{\circ} \mathrm{C}\right)$ carbogenated ACSF. The slices were immediately placed in a solution of carbogenated ACSF and incubated at $34^{\circ} \mathrm{C}$ for a minimum of $1 \mathrm{hr}$. A slice containing caudal regions of the DR was then transferred to a recording chamber where it was submerged and continuously superfused at a rate of $2.5-3 \mathrm{ml} / \mathrm{min}$ with carbogenated ACSF, which had been prewarmed to $34 \pm 0.2^{\circ} \mathrm{C}$. The composition of the ACSF was (in $\mathrm{mM}$ ) NaCl, 126; KCl, $2.5 ; \mathrm{NaH}, \mathrm{PO}_{4}$, 1.2; $\mathrm{MgCl}_{2}, 1.2 ; \mathrm{CaCl}_{2}, 2.4 ;$ D-glucose, $11 ; \mathrm{NaHCO}_{3}, 25$. To evoke synaptic potentials, a bipolar tungsten stimulating electrode, connected to a stimulus isolating unit, was placed in, or adjacent to, the DR.

Intracellular recording. Neurons were impaled with glass microelectrodes filled with $2 \mathrm{M} \mathrm{KCl}(50-120 \mathrm{M} \Omega)$, connected to the headstage of an Axoclamp 2A amplifier. Only ncurons with the charactcristic complex synaptic responses, and that responded to the application of the 5-HT 1 agonist 5-carboxamidotryptamine (5-CT) with an inwardly rectifying potassium conductance, were studied. Synaptic potentials were recorded in bridge current-clamp mode upon stimulation via the bipolar electrode. Stimuli (10-40 V, 1-2 msec) were presented either singly or in pairs (interstimulus interval, $20 \mathrm{msec}$ ). In the presence of neurotransmitter agonists, current of the appropriate sign was applied to the neuron via the balanced bridge circuit to keep it at the original membrane potential $\left(V_{m}\right)$. The fast, amino acid-dependent, depolarizing synaptic potentials (DSPs; Pan and Williams, 1989a) were blocked with a cocktail containing $10 \mu \mathrm{M}$ 6-cyano-7-nitroquinoxaline-2,3-dione (CNQX), 50 $\mu \mathrm{M}$ DL-2-amino-5-phosphonovaleric acid (APV), and $50 \mu \mathrm{M}$ picrotoxin. Slow EPSPs (sEPSPs) were blocked with prazosin (100 nM), and IPSPs were blocked with cyanopindolol $(1 \mu \mathrm{M})$, or reduced with $m$-trifluoromethylphenylpiperazine (TFMPP, $1 \mu \mathrm{M}$ ). For voltage-clamp experiments, the discontinuous single-electrode voltage-clamp technique (switching frequency, 3.4-4.2 kHz) was used; electrodes were coated with Sylgard (Dow-Corning) to reduce capacitance. Headstage voltage was continuously monitored to ensure proper voltage clamp; headstage voltage pulses had to be square, and electrode settling after the current passing phase had to be complete prior to voltage sampling for the clamp to be considered acceptable. Neurons were routinely held near their resting membrane potential at $-60 \mathrm{mV}\left(V_{h}\right)$. For ramp experiments, the voltage was slowly $(2 \mathrm{sec})$ ramped from $-60 \mathrm{mV}$ to -125 $\mathrm{mV}$ and then held for $2 \mathrm{sec}$ to stabilize the membrane before ramping gradually $(\simeq 20 \mathrm{sec})$ to $-40 \mathrm{mV}$. In a few experiments, the voltage was ramped from $-115 \mathrm{mV}$ to $-40 \mathrm{mV}$. Ramps were digital averages of two successive responses taken $30 \mathrm{sec}$ apart. In some experiments, voltage steps of $1 \mathrm{sec}$ duration were applied to potentials both negative and positive to $V_{h}$. Data were corrected for any electrode offset observed at the end of an experiment. Digital averages of three successive synaptic responses, taken at $60 \mathrm{sec}$ intervals, were used for figures and for data analysis. The maximum amplitude of each synaptic response was taken as the magnitude of that response.

All data were stored on computer for on-line analysis using the pCLAMP program (Axon Instruments) or digitally on videotape for playback and off-line analysis using a Nicolet 4094 digital oscilloscope. Current and voltage data were recorded continuously during an experiment with a pen recorder (Gould Brush 2200). For some figures, current records were digitally subtracted using Axum software (TriMetrix, Seattle, WA). Data are expressed as percentage inhibition of control values; averages are presented as means \pm SEM. Preparations served as their own controls; all data are from preparations that showed significant recovery upon washout. Statistical comparisons were performed using a Student's $t$ test. Statistical differences were considered significant at $p \leq 0.05$.

Drugs were dissolved in warmed, carbogenated ACSF just prior to use and applied via bath perfusion. NPY, peptide YY (PYY), and NPY 13-36 were obtained from INRS, Pointe-Claire, Quebec, and dissolved in ACSF in a final volume of $10 \mathrm{ml}$ prior to use. C2-NPY was a gift of Dr. J. L. Krstenansky (Merrell Dow). Cyanopindolol was a gift of Sandoz (Canada). TFMPP was obtained from RBI (Natick, MA). All other drugs were obtained from Sigma (St. Louis, MO).

\section{Results}

\section{NPY/PYY reduce slow but not fast synaptic potentials}

Focal electrical stimulation of DR elicits a complex synaptic potential in DR serotonergic neurons that consists of fast and slow components as shown in Figure $1 a$. A fast DSP is first elicited that is sensitive to antagonists of quisqualate/kainate and NMDA excitatory amino acid receptors (Pan and Williams,
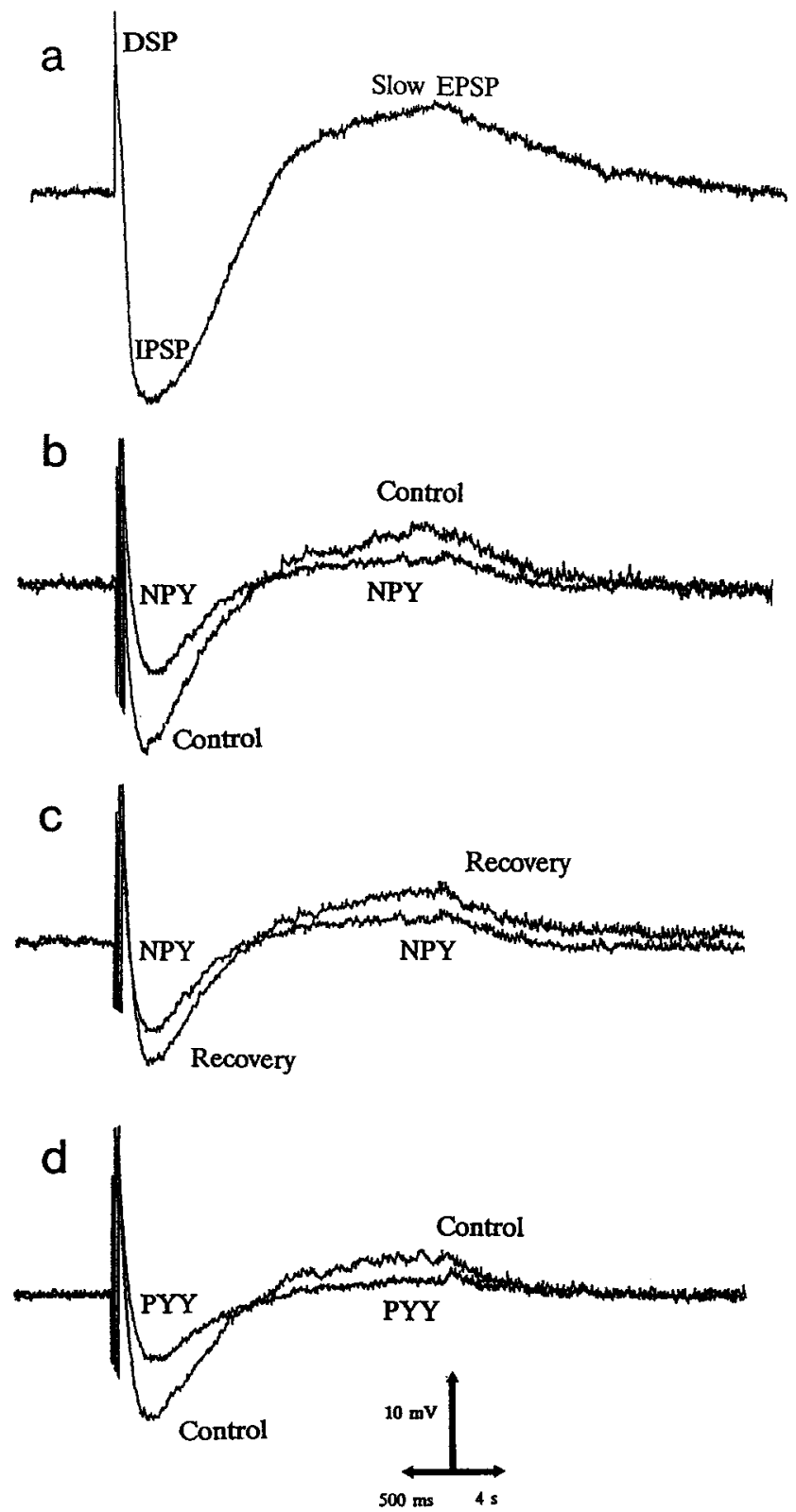

Figure 1. NPY and PYY inhibit only slow synaptic potentials in the rat DR nucleus. $a$, Complex synaptic potential evoked in a DR nucleus neuron by focal electrical stimulation. See text for detailed description. Digital sampling rate was slowed eightfold at the center of the trace to capture the decay of the sEPSP. $b$, Superimposed traces of synaptic potentials in control and after application of $1 \mu \mathrm{M}$ NPY; the peptide inhibited both of the slow components. $c$, NPY trace from $b$ is superimposed on trace taken after $30 \mathrm{~min}$ wash, demonstrating recovery. $d$, PYY $(1 \mu \mathrm{M})$ inhibits the slow synaptic potentials of the cell in $b$ and $c$ (recovery not illustrated). The peptides were applied by superfusion for 3-4 min; maximal peptide effect was observed 5-10 min following the start of washout.

$1989 \mathrm{a}, \mathrm{b}$ ), as well as to antagonists of the $\mathrm{GABA}_{\mathrm{A}}$ receptors (the intracellular electrodes used in these experiments contained $\mathrm{KCl}$, which shifted the chloride equilibrium potential positive to rest, thus producing a depolarizing response; Williams et al., 1988). The slow components consist of a potassium-dependent IPSP, mediated by 5-HT ${ }_{1 \mathrm{~A}}$ autoreceptors (Yoshimura and Higashi, 1985; Pan and Williams, 1989b; Bobker and Williams, 1990), 


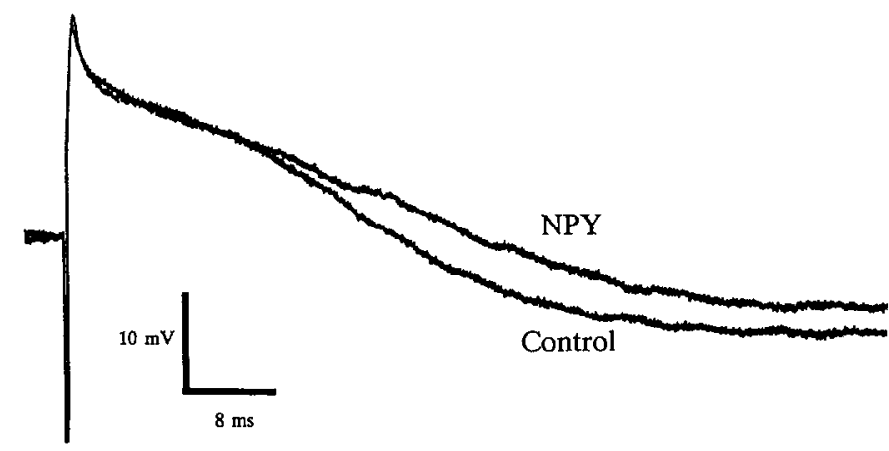

Figure 2. NPY and PYY have no effect on amino acid-mediated synaptic responses in the rat DR nucleus. Superimposed are the DSP evoked in control and in the presence of NPY $(1 \mu \mathrm{M})$. NPY has no effect on the DSP, while it inhibits the IPSP.

followed by a sEPSP, mediated by $\alpha_{1}$-adrenoceptors (Yoshimura et al., 1985; Pan and Williams, 1989).

Bath application of $1 \mu \mathrm{M}$ NPY caused a reduction both in the IPSP (by $33.3 \pm 4.4 \% ; n=10, p<0.0001$ ), and the SEPSP (by $40.2 \pm 7.8 \% ; n=11, p<0.001$; Fig. $1 b$ ). This inhibition was slow (5-10 min) in onset and reversed upon prolonged washout (Fig. lc). All data reported are from preparations demonstrating substantial ( $>90 \%$ ) recovery from peptide effect. The NPY analog, PYY $(1 \mu \mathrm{M})$, which shares $70 \%$ sequence homology with, and a high degree of analogy to, NPY (Tatemoto, 1982), also reversibly inhibited the IPSP by $45.4 \pm 4.0 \%(n=9, p<0.001)$, and the sEPSP by $31.2 \pm 6.0 \%(n=6, p<0.005)$ (Fig. $1 d)$. Because the effects of NPY and PYY on slow synaptic responses were statistically indistinguishable, they were used interchangably in all following experiments. By contrast, neither NPY nor PYY had an effect on the fast synaptic component $(n=11, p$ $>0.5$; Fig. 2).

\section{NPY/PYY inhibit isolated slow synaptic responses}

To determine if the slow components of the complex synaptic response were modulated individually, we isolated the slow synaptic responses by pharmacological means and then studied the effect of NPY/PYY. The DSP was blocked with a cocktail containing supramaximal concentrations of antagonists to quisqualate/kainate and NMDA receptors and $\mathrm{a} \mathrm{GABA}_{\mathrm{A}}$ (chloride) channel blocker (Pan and Williams, 1989a; see Materials and Methods). Additionally, the sEPSP was completely eliminated in the presence of $100 \mathrm{nM}$ prazosin, a selective $\alpha_{1}$-adrenoceptor antagonist (Pan and Williams, 1989b; Bobker and Williams, 1990b). PYY reduced the resulting isolated IPSP by $22.0 \pm$ $4.2 \%(n=3, p<0.025$; Fig. $3 a)$, indicating that the IPSP inhibition was direct.

Because the 5-HT $\mathrm{HA}_{1 \mathrm{~A}}$ antagonist spiperone also blocks $\alpha_{1}$-adrenoceptors (Pan and Williams, 1989a), we explored other pharmacological means of isolating the sEPSP. Blockade of both 5- $\mathrm{HT}_{1 \mathrm{~A}}$ and 5- $\mathrm{HT}_{1 \mathrm{~B}}$ receptors with $1 \mu \mathrm{M}$ cyanopindolol (Bobker and Williams, 1990b) in the presence of the amino acid antagonist cocktail completely isolated the SEPSP. In the presence of cyanopindolol, PYY reversibly inhibited the sEPSP by $35.0 \pm$ $8.6 \%(n=3, p<0.025$; Fig. $3 b)$.

To determine whether inhibition of the IPSP by NPY/PYY receptors occurred via the same mechanism as the presynaptic $5-\mathrm{HT}_{18}$ receptor that inhibits release of 5-HT in DR (Bobker and Williams, 1990a; J. T. Williams, personal communication),
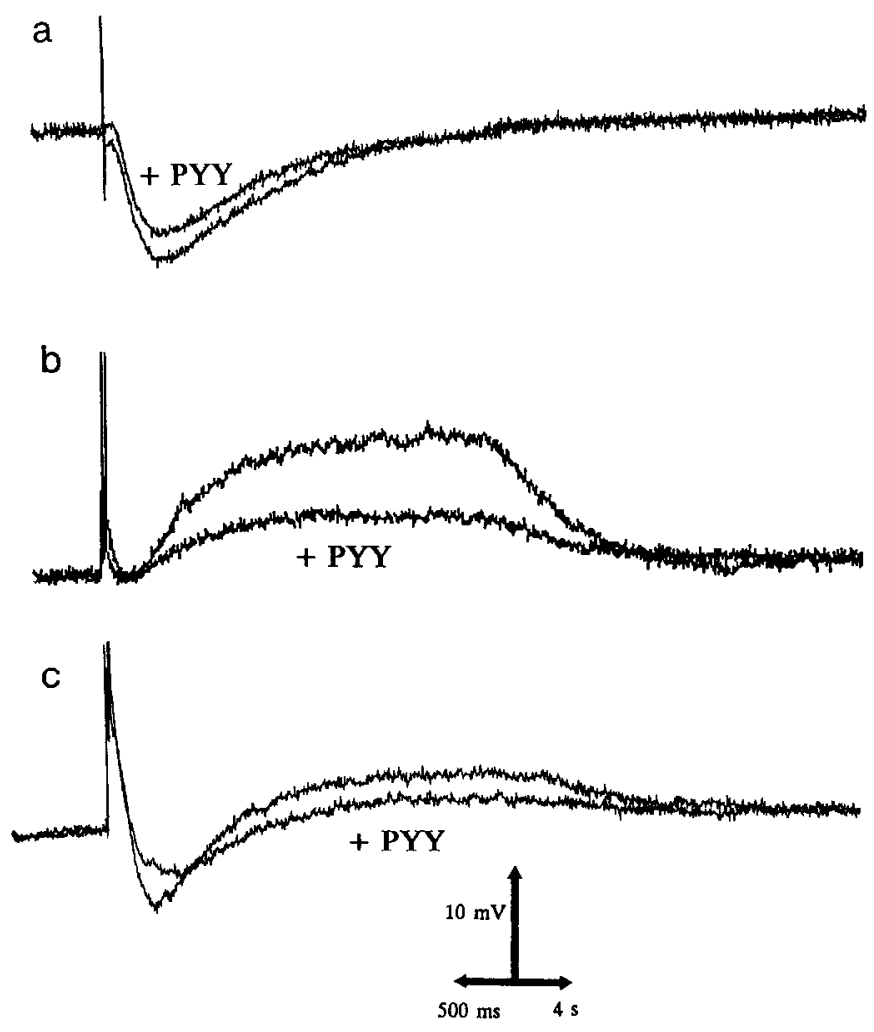

Figure 3. PYY inhibits isolated slow synaptic potentials in the DR nucleus. $a$, Superimposed are the pharmacologically isolated IPSP in control (a cocktail of the amino acid receptor antagonists CNQX/APV/ picrotoxin, and prazosin, to block the SEPSP) and after addition of PYY $(1 \mu \mathrm{M}) . b$, The sEPSP was isolated pharmacologically with the amino acid receptor antagonist cocktail and cyanopindolol, to block the IPSP. The isolated sEPSP is also inhibited by PYY $(1 \mu \mathrm{M}) . c$, PYY inhibits the IPSP and SEPSP in the presence of $1 \mu \mathrm{M}$ TFMPP, a 5-HT ${ }_{1 \mathrm{~B}}$ receptor antagonist.

we examined the action of the peptide in the presence of a high concentration of the 5- $\mathrm{HT}_{1 \mathrm{~B}}$-selective agonist TFMPP $(1 \mu \mathrm{M})$. TFMPP caused an inhibition of evoked, 5-HT-mediated responses (Bobker and Williams, 1990a,b), reducing the IPSP by $61.7 \pm 9.8 \%(n=5)$. The IPSP remaining after TFMPP treatment was reversibly reduced by PYY (by $36.3 \pm 6.1 \% ; n=4$, $p<0.01$; Fig. $3 c$ ). As well, PYY reduced the sEPSP in the presence of TFMPP (and the amino acid antagonist cocktail) by $21.5 \pm 4.2 \%(n=3, p<0.025$; not illustrated $)$.

\section{NPY/PYY have no effect on postsynaptic conductances}

To determine the locus of the peptides' action on synaptic responses, we applied single-microelectrode voltage clamp to DR neurons (Finkel and Redman, 1984; Williams et al., 1988; Pan and Williams, 1989) to test whether the peptides affected voltage and ligand-induced conductances. Application of $1 \mu \mathrm{M}$ NPY or PYY alone did not affect the resting membrane conductance of DR neurons, nor did it affect steady-state voltage-dependent conductances elicited by a slow $(\simeq 20 \mathrm{sec})$, steady voltage ramp from -115 to $-40 \mathrm{mV}$. At the same time, the slow synaptic potentials were inhibited (Fig. 4).

Having seen no effect on resting membrane conductances, we next determined whether the peptides modulated ligand-induced conductances, as has been postulated for NPY in locus coeruleus neurons (Illes and Regenold, 1990). Selective agonists were applied to activate either the postsynaptic 5-HT receptors 
a
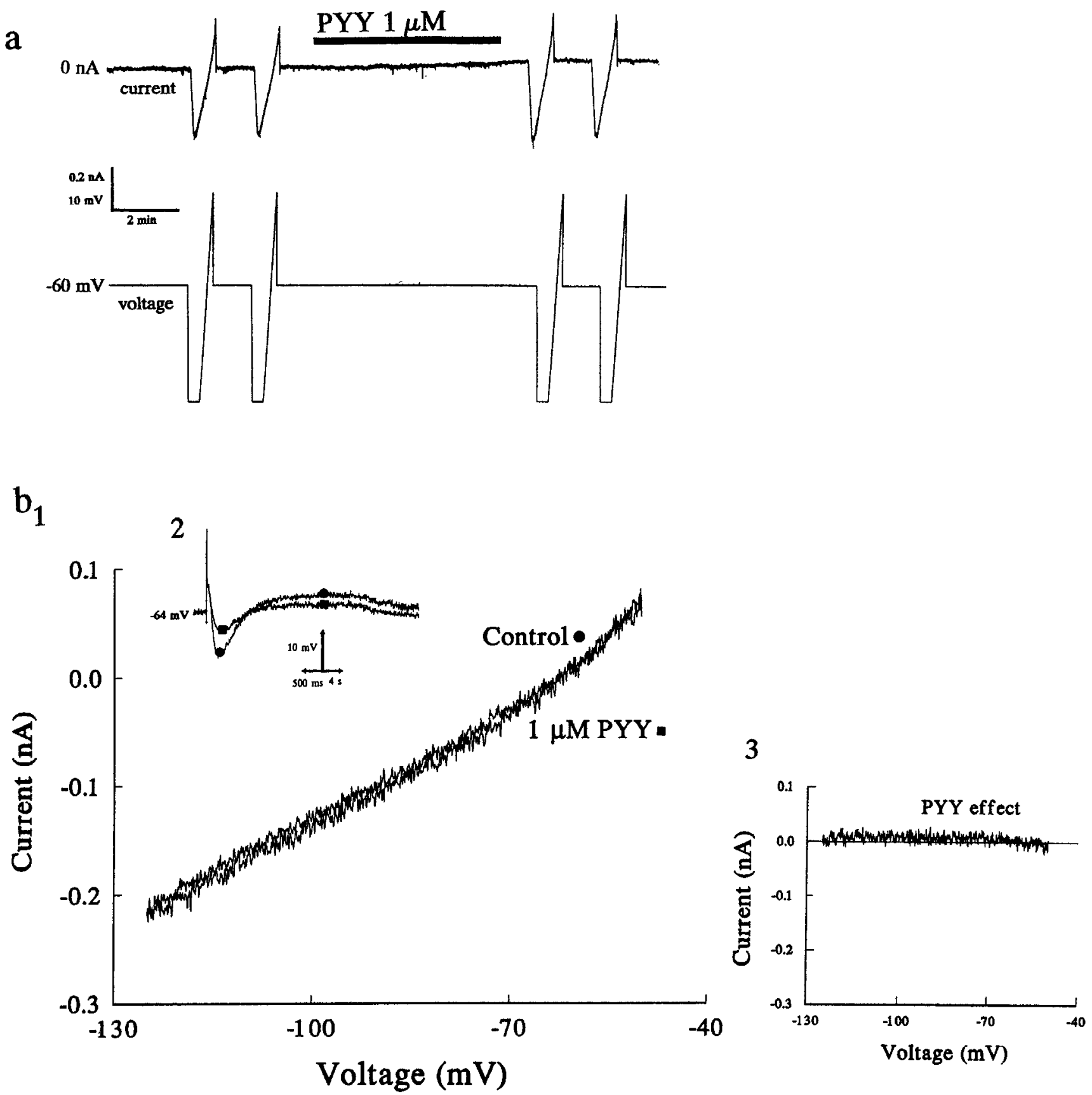

Figure 4. PYY at $1 \mu \mathrm{M}$ affects neither resting nor voltage-activated membrane conductances. $a$, Chart record of the resting membrane current in a DR neuron held near rest in voltage clamp. A slow voltage ramp protocol (from -115 to $-40 \mathrm{mV}$ ) was applied; voltage range was corrected for electrode offset. Application of $1 \mu \mathrm{M}$ PYY does not alter the resting membrane current. $b_{l}$, Superimposed are the steady-state $I-V$ relationship in the absence (control, $\ominus$ ) and in the presence of $1 \mu \mathrm{M}$ PYY $(\square)$. Inset $b$, Superimposed are the synaptic potentials evoked in control $(0)$ and in the presence of $1 \mu \mathrm{M}$ PYY $(\square)$, showing the inhibition of both the IPSP and sEPSP in the DR neuron in $a$. Inset $b_{3}$, Digital subtraction of the steadystate $I-V$ relationships in $b_{l}$.

or $\alpha_{1}$-adrenoceptors; we then examined whether coapplication of the peptide altered the ligand-induced changes in membrane conductance, while at the same time examining the effects of the peptides on synaptic potentials.

Application of $100 \mathrm{~nm} 5-\mathrm{CT}$, a full agonist at the postsynaptic 5-HT ${ }_{1 \mathrm{~A}}$ receptors (Hoyer, 1988; Williams et al., 1988; Pan et al., 1989; Andrade and Chaput, 1991), hyperpolarized DR neurons in current clamp (Williams et al., 1988). This was accompanied by a marked reduction of the IPSP; the sEPSP was shortened but not greatly reduced in amplitude (Fig. $5 a_{2}$ ). When the cells were held near rest in voltage clamp $\left(V_{h}=-65 \mathrm{mV}\right), 5-\mathrm{CT}$ elicited an outward current, which rectified inwardly (Fig. $5 a_{l, 4}$ ) as previously reported (Williams et al., 1988). Voltage step commands ( $1 \mathrm{sec}$ ) were also applied to different potentials (Fig. $5 a_{3}$ ); no significant differences were observed in current values measured at the end of a $1 \mathrm{sec}$ voltage step and during the slow voltage ramp (Fig. $5 a_{1}$ ), indicating that the ramp measured steadystate membrane conductances (Williams et al., 1988). Application of PYY $(1 \mu \mathrm{M})$ in the presence of 5-CT had no effect on the time-dependent (Fig. $5 b_{t, 3}$ ) or steady-state membrane con- 

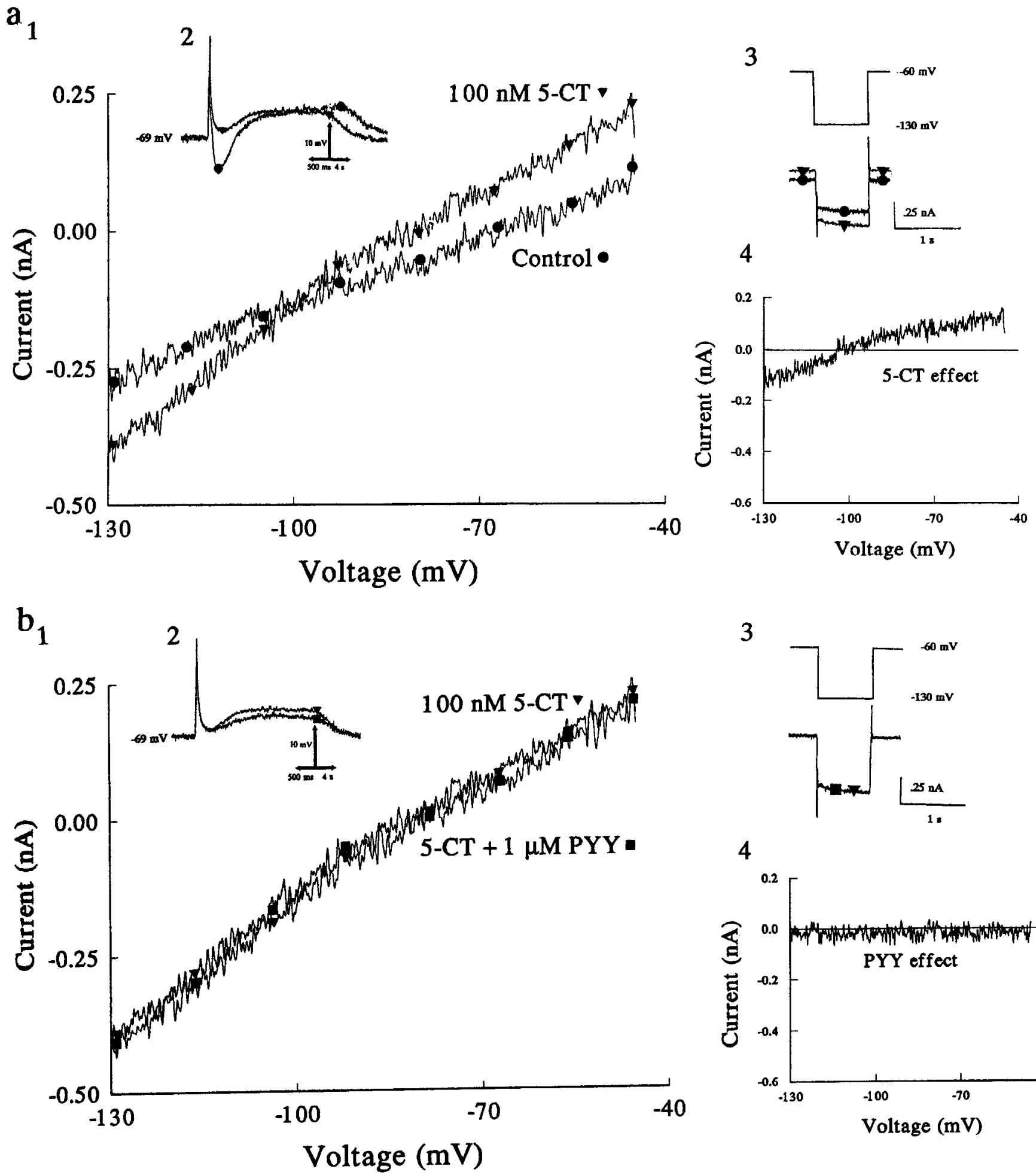

3

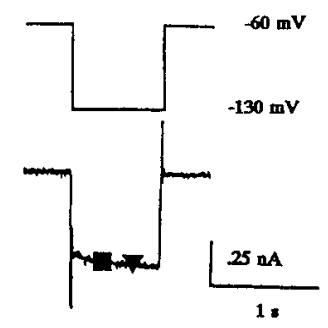

4

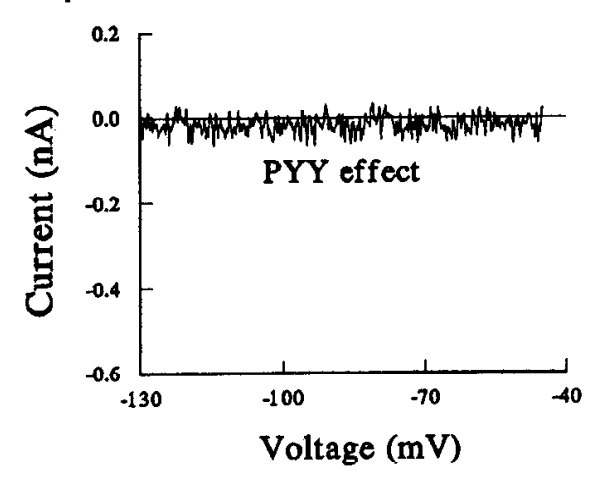

Figure 5. PYY at $1 \mu \mathrm{M}$ does not alter the 5-HT $1 \mathrm{~A}$ receptor-mediated membrane conductance while inhibiting the sEPSP in DR neurons. $a_{1}$, Application of $100 \mathrm{nM} 5-C T$ causes a hyperpolarization or outward current in DR neurons, with a marked reduction of the IPSP. Superimposed are the steady-state current-voltage (I-V) relationship in a DR neuron obtained by application of a slow depolarizing voltage ramp from - 125 to $-40 \mathrm{mV}$ (the voltage range has been corrected for electrode offset). Symbols (control, $, 5-C T, \nabla)$ represent the values of membrane currents measured at the end of $1 \mathrm{sec}$ voltage-clamp steps to different potentials (inset $a_{3}$ ). Inset $a_{2}$, Synaptic potentials, evoked at the same membrane potential in control and in the presence of 5-CT. The IPSP is reduced by 5-CT, the sEPSP is curtailed. The neuron was depolarized with current to the same potential as control in 5-CT to compare synaptic potentials. Inset $a_{4}$, Digital subtraction of the ramp currents in $a_{l}$, showing the inwardly rectifying conductance induced by 5-CT. $b_{I}$, Steady-state $I-V$ relationship of the neuron in $a$ in the presence of $5-C T$ alone $(\nabla)$ superimposed on the $I-V$ relationship in the presence of 5-CT with $1 \mu \mathrm{M}$ PYY $(\square)$. Inset $b_{2}$, The synaptic potentials evoked in 5-CT alone and in 5-CT with PYY showing the inhibition of the SEPSP. $b_{3}$, digital subtraction of the slow ramp $I-V$ relationships in $b_{1}$. 

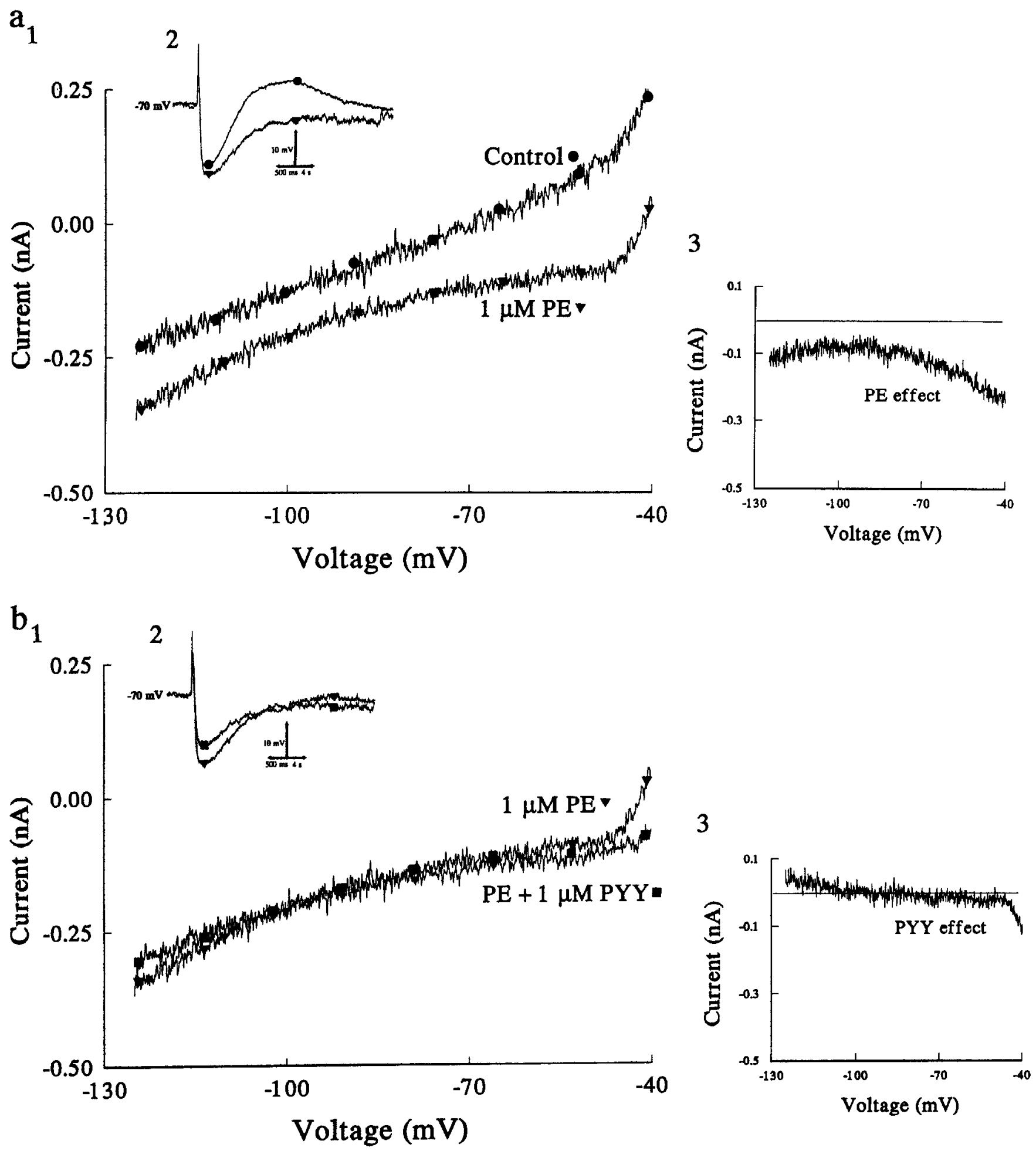

Figure 6. PYY at $1 \mu \mathrm{M}$ does not alter $\alpha_{1}$-adrenoceptor-mediated membrane conductance changes, while inhibiting the IPSP in a DR neuron. $a$, The $\alpha_{1}$-agonist PE $(1 \mu \mathrm{M})$ evokes a steady-state inward current in voltage-clamped DR neurons. $a_{l}$, The steady-state $I-V$ curves in the absence of PE (control, $\bullet$ ) and in the presence of $1 \mu \mathrm{M}$ PE $(\nabla)$ are shown superimposed. Symbols represent the membrane current values from voltage steps as in Figure 4. Inset $a_{2}$, the synaptic potentials, evoked at the same membrane potential in control and in the presence of PE. The neuron was hyperpolarized to the control potential for comparison of synaptic potentials. The sEPSP is occluded by the application of PE. Inset $a_{3}$, Digital subtraction of the steady-state $I-V$ curves in $a_{l} . b$, Steady state $I-V$ curves in PE ( $\left.\nabla\right)$, and in PE with $1 \mu \mathrm{M}$ PYY ( $)$. Insets as in $a$. Although PYY has no effect on the membrane currents, the IPSP evoked in current clamp is inhibited.

ductances (Fig. $5 b_{1,4}$ ) over the voltage range examined. However, the sEPSP recorded in current clamp was reversibly inhibited by $37.95 \pm 7.2 \%\left(n=5, p<0.005\right.$; Fig. $\left.5 b_{2}\right)$.

In analogous experiments, the $\alpha_{1}$-adrenoceptor agonist phen- ylephrine (PE, $1 \mu \mathrm{M}$; Baraban and Aghajanian, 1989) induced a steady-state inward current near rest (Fig. $6 a_{1,3}$ ), as well as appearing to reduce an outward current in the depolarizing region of the current-voltage relationship (Fig. $6 a_{1,3}$; Pan and Wil- 

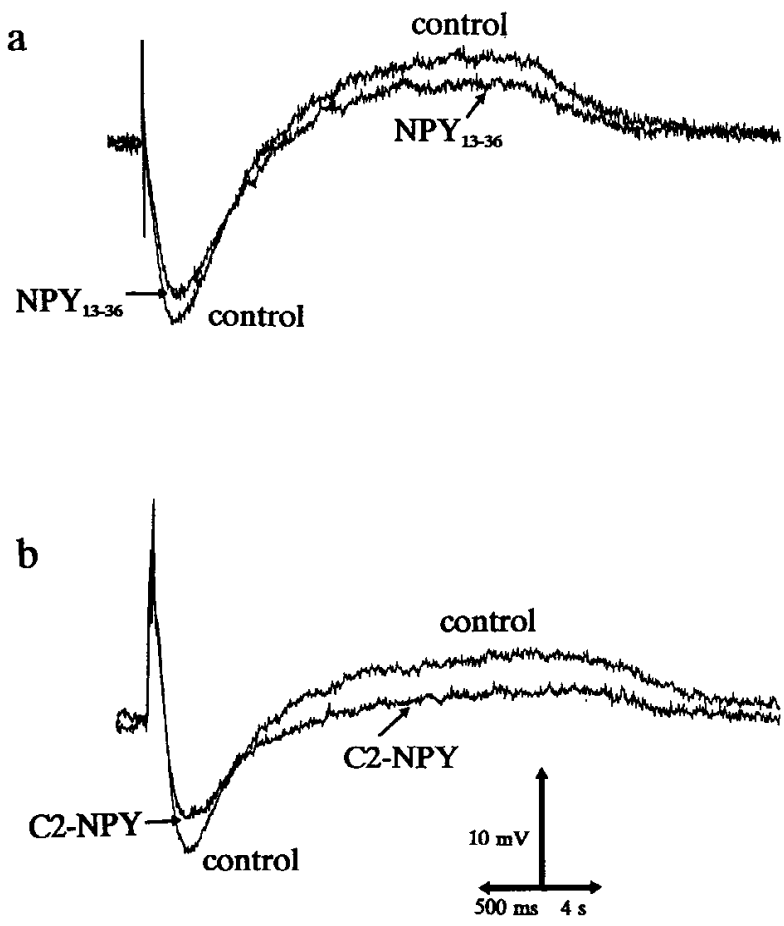

Figure 7. $\mathrm{Y}_{2}$ receptor agonists inhibit slow synaptic potentials in the DR. a, Synaptic potentials evoked in a DR neuron in control and after application of $1 \mu \mathrm{M}$ NPY 13-36 are shown superimposed. $b$, Synaptic potentials in a different DR neuron in control and after application of C2-NPY. Membrane potential was the same in control and peptide for each cell. Responses recovered upon washout.

liams, 1989), corresponding to a depolarization in current clamp; the sEPSP was also occluded (Fig. $6 a_{2}$ ). Application of PYY (1 $\mu \mathrm{M})$ did not significantly alter the steady-state membrane conductance in the presence of PE (Fig. $6 b_{1.4}$ ), but the isolated IPSP, recorded in current clamp, was inhibited by $31.0 \pm 9.9 \%(n=$ $4, p<0.005$; Fig. $6 b_{2}$ ).

\section{Synaptic effects of NPY/PYY are mimicked by $Y_{2}$ receptor agonist}

Two receptors for NPY/PYY have been identified, which can be differentiated on the basis of agonist fragments of NPY or PYY. The $Y_{1}$ receptors require the entire, intact peptide, while the $Y_{2}$ receptors can be activated by amidated C-terminal peptide fragments as short as NPY 13-36 (Wahlestedt et al., 1986). Because presynaptic inhibition mediated by NPY at peripheral (Wahlestedt et al., 1986) and central mammalian synapses (Colmers et al., 1991) has been shown to be mediated by $Y_{2}$ receptors, we examined the effect of NPY 13-36 on slow synaptic responses in DR to determine whether this effect was also mediated by a $Y_{2}$ receptor. A $1 \mu \mathrm{M}$ concentration of NPY 13-36 reversibly inhibited IPSP and sEPSP by $15.88 \pm 1 \%(n=3, p$ $<0.005)$ and $26.58 \pm 10.82 \%(n=2, p<0.25)$, respectively (Fig. 7a). Although the inhibition of the sEPSP was not statistically significant, NPY 13-36 clearly demonstrated a reversible inhibition of this response.

To examine further the question of receptor subtype, we examined whether the recently developed $\mathrm{Y}_{2}$ receptor ligand $\left[\mathrm{Cys}^{2}\right.$, 8-aminooctanoic acid ${ }^{5.24}$, D-Cys ${ }^{27}$ ]-NPY (C2-NPY, MDL 29,616; McLean et al., 1990) affected slow synaptic potentials in DR. Application of C2-NPY $(1 \mu \mathrm{M})$ inhibited the IPSP by $33.2 \pm$ $0.5 \%(n=2, p<0.01)$, and the SEPSP by $47.1 \pm 0.8 \%(n=2$, $p<0.01$; Fig. $7 b$ ). The inhibition of both slow synaptic potentials by C2-NPY was reversible (not illustrated).

\section{Discussion}

In this study, we have demonstrated that NPY and PYY inhibit both hyperpolarizing and depolarizing slow synaptic potentials in DR, while not measurably affecting the fast synaptic potentials. This observation is in contrast to their previously reported effect in the hippocampus (Colmers et al., 1987, 1991). These actions are presynaptic since there was no effect on resting, voltage-activated, or agonist-induced membrane conductances. As well, there was no effect on the fast, amino acid-mediated synaptic responses, consistent with a selective presynaptic action at serotonergic and noradrenergic terminals alone.

The actions of NPY/PYY are mimicked consistently, though less potently, by the carboxy-terminal NPY 13-36 fragment. The $Y_{2}$ receptor-selective ligand C2-NPY is an agonist as well. These data suggest that the actions of NPY/PYY may be mediated by the activation of a presynaptic $Y_{2}$ receptor, as has already been demonstrated in the hippocampus (Colmers et al., 1991) and elsewhere (Wahlestedt et al., 1986). In most systems, the agonist fragment is less potent than the intact peptide; in rat hippocampus NPY $13-36$ is about $50 \%$ as potent as NPY (Colmers et al., 1991). Interestingly, the peptidergic inhibition of the IPSP was reduced after blockade of $\alpha_{1}$-adrenoceptors, suggesting that a portion of the IPSP was facilitated by noradrenergic excitation of neighboring DR neurons.

Although this study did not address in detail the mechanism of presynaptic action by NPY/PYY, it seems clear that the peptidergic inhibition of the IPSP appears to be independent of the presynaptic $5-\mathrm{HT}_{1 \mathrm{~B}}$ receptor and its mechanism of action, as PYY inhibited the IPSP remaining after a supramaximal concentration of the 5-HT ${ }_{1 \mathrm{~B}}$ agonist TFMPP was applied. There is evidence in hippocampus (Colmers et al., 1988) and in cultured dorsal root ganglion neurons (Bleakman et al., 1991) that $\mathrm{Y}_{2}$ receptors inhibit $\mathrm{Ca}^{2+}$ influx. However, the mechanism of $Y_{2}$ presynaptic action in DR will need to be elucidated in detail, perhaps aided by the likelihood that there are two presynaptic mechanisms by which the IPSP can be inhibited.

The present results indicate that NPY and PYY modulate slow synaptic transmission in DR by a presynaptic mechanism. This means that at central, as well as peripheral, synapses (Wahlestedt et al., 1986) NPY can inhibit the release of NA. The observed inhibition by NPY of a 5-HT-induced synaptic response (probably through inhibition of release) is a novel finding. Data from microdialysis of hypothalamic nuclei with NPY show a reduction in levels of NA, 5-HT, and their metabolites (Shimizu and Bray, 1989), suggesting a presynaptic inhibitory action, as we have observed here. Although NPY has been reported to modulate the NA response of the locus coeruleus neurons via a postsynaptic mechanism (Illes and Regenold, 1990), we observed no such interaction in the DR.

The inhibition by NPY of both slow inhibitory and excitatory synaptic inputs to DR neurons appears contradictory. There is, however, a potential explanation for this apparent contradiction. Noradrenergic tone is required for the tonic activity of DR neurons observed in vivo (Baraban and Aghajanian, 1980). Release of NPY onto its receptors in DR would be expected to reduce this activity. At the same time, NPY would be expected to reduce the $5-\mathrm{HT}_{1 \mathrm{~A}}$ receptor-mediated inhibition of the DR 5-HT cclls. Because the action of NPY is entirely presynaptic, other mediating or modulating influences on the postsynaptic 
membrane will remain unaltered. We suggest that the release of NPY could therefore induce a state of "quiet readiness" in DR neurons, where the tonic level of activity is lowered, but that the response to suprathreshold stimuli (such as from the habenular excitatory amino acid inputs; Kalen et al., 1985, 1986) will be enhanced, because the activity-dependent autoinhibition, caused by the release of 5-HT, is attenuated. A similar change of state is induced by NA in hippocampal pyramidal neurons, albeit by a postsynaptic mechanism (Madison and $\mathrm{Ni}$ coll, 1982).

\section{References}

Aghajanian GK, Wang RY (1977) Habernular and other midbrain raphe afferents demonstrated by a modified retrograde tracing technique. Brain Res 122:229-242.

Aitken A, Tork I (1988) Early development of serotonin-containing neurons and pathways as seen in wholemount of fetal rat brains. $J$ Comp Neurol 274:32-47.

Andén NE, Dahlstrom A, Fuxe K, Larsson K, Olson L, Ungerstedt U (1966) Ascending monoamine neurons to the telencephalon and diencephalon. Acta Physiol Scand 67:313-326.

Andrade R, Chaput Y (1991) The electrophysiology of serotonin receptor subtypes. In: Serotonin receptor subtypes: basic and clinical aspects (Peroutka SJ, ed), pp 103-124. New York: Wiley-Liss.

Azmitia EC, Sègal M (1978) An autoradiographic analysis of the differential ascending projections of the dorsal and median raphe nuclei in the rat. J Comp Neurol 179:641-668.

Baraban JM, Aghajanian GK (1980) Suppression of firing activity of 5-HT neurons in the dorsal raphe by alpha-adrenoceptor antagonists. Neuropharmacology 19:355-363.

Bartfai T, Iverfeldt K, Fisone G, Serfözö P (1988) Regulation of the release of coexisting neurotransmitters. Ann Rev Pharmacol Toxicol 28:285-310.

Bobker DH, Williams JT (1990a) Serotonin-mediated inhibitory postsynaptic potentials in guinea pig prepositus hypoglossi and feedback inhibition by serotonin. J Physiol (Lond) 422:447-462.

Bobker DH, Williams JT (1990b) Ion conductances affected by 5-HT receptor subtypes in mammalian neurons. Trends Neurosci 13:169173.

Chazal G, Ralston JH III (1987) Serotonin-containing structures in the nucleus raphe dorsalis of the cat: an ultrastructural analysis of dendrites, presynaptic dendrites and axon terminals. J Comp Neurol 259:327-329.

Colmers WF, Lukowiak KD, Pittman QJ (1987) Presynaptic action of neuropeptide $\mathrm{Y}$ in CAl of rat hippocampal slice. J Physiol (Lond) 383:285-299.

Colmers WF, Lukowiak KD, Pittman QJ (1988) Neuropeptide K action in the rat hippocampal slice: site and mechanism of presynaptic inhibition. J Neurosci 8:3827-3837.

Colmers WF, Klapstein GJ, Fournier A, St-Pierre S, Treherne KA (1991) Presynaptic inhibition by neuropeptide $Y$ in rat hippocampal slice in vitro is mediated by a $\mathrm{Y}_{2}$ receptor. $\mathrm{Br} \mathrm{J}$ Pharmacol 120:4144.

de Quidt ME, Emson PC (1986) Distribution of neuropeptide Y-like immunoreactivity in the rat central nervous system. II. Immunohistochemical analysis. Neuroscience 18:545-618.

Ekblad E, Edvinson L, Wahlestedt C, Uddman R, Häkanson R, Sundler $F$ (1984) Neuropeptide $Y$ co-exists and co-operates with noradrenaline in perivascular nerve fibers. Regul Pept 8:225-235.

Finkel AS, Redman S (1984) Theory and operation of single microelectrode voltage clamp. J Neurosci Methods 11:101-127.

Fuxe K, Jonsson G (1974) Further mapping of central 5-hydroxytryptamine neurons: studies with the neurotoxic dihydroxytryptamine. In: Advances in biochemical psychopharmacology, Vol 10 Serotonin: ncw vistas, histochcmistry and pharmacology. (Costa E, Gessa GL, Sandler M, eds), pp 1-12. New York: Raven.

Hoyer D (1988) Functional correlates of serotonin 5-HT, recognition sites. J Recept Res 8:59-81.

Illes P, Regenold JT (1990) Interaction between neuropeptide $Y$ and noradrenaline on central catecholamine neurons. Nature 344:62-63.

Kalen P, Karlson M, Wiklund L (1985) Possible excitatory amino acid afferents to nucleus raphe dorsalis of the rat investigated with retro- grade wheat germ agglutinin and $\mathrm{D}-\left[{ }^{3} \mathrm{H}\right]$-aspartate tracing. Brain Res 360:285-297.

Kalen P, Pritzel M, Nieoullon A, Wiklund L (1986) Further evidence for excitatory amino acid transmission in the lateral habernular projection to the rostral raphe nuclei: lesion-induced decrease of high affinity glutamate uptake. Neurosci Lett 68:35-40.

Lundberg JM, Hökfelt T (1986) Multiple co-existence of peptides and classical transmitters in peripheral autonomic and sensory neuronsfunctional and pharmacological implication. In: Progress in brain research, Vol 68 (Hökfelt T, Fuxe K, Pernow B, eds), pp 241-262. Amsterdam: Elsevier.

Lundberg JM, Stjärne L (1984) Neuropeptide Y (NPY) depresses the secretion of ${ }^{3} \mathrm{H}$-noradrenaline and the contractile response evoked by field stimulation in rat vas deferens. Acta Physiol Scand 120:477479.

Lundberg JM, Tatemoto K (1982) Pancreatic polypeptide family (APP, BPP, NPY, and PYY) in relation to $\alpha$-adrenoceptor-resistant sympathetic vasoconstriction. Acta Physiol Scand 116:393-403.

Lundberg JM, Hua XY, Franco-Cereceda A (1984) Effects of neuropeptide $Y$ (NPY) on mechanical activity and neurotransmission in the heart, vas deferens and urinary bladder of the guinea-pig. Acta Physiol Scand 121:325-332.

Madison DV, Nicoll RA (1982) Noradrenaline blocks accommodation of pyramidal cell discharge in hippocampus. Nature 299:636-638.

Martel J, Fournier A, St Pierre S, Quirion R (1990) Quantitative autoradiographic distribution of [ $\left.{ }^{125} \mathrm{I}\right]$ Bolton-Hunter neuropeptide $Y$ receptor binding sitcs in rat brain. Comparison with [12sI]-peptide YY receptor sites. Neuroscience 36:255-283.

McLean LR, Buck SH, Krstenansky JL (1990) Examination of the role of the amphipathic $\alpha$-helix in the interaction of neuropeptide $Y$ and active cyclic analogues with cell membrane receptors and dimyristoylphosphatidylcholine. Biochemistry 29:2016-2022.

Mulligan KA, Tork I (1987) Serotonergic axons form basketlike terminals in cerebral cortex. Neurosci Lett 81:7-12.

Mulligan KA, Tork I (1988) Serotonergic innervation of the cat cerebral cortex. J Comp Neurol 270:86-110.

O'Donoghue TL, Chronwall BM, Pruss RM, Mezey E, Kiss JZ, Eiden LE, Massari VJ, Tessel RE, Pickel VM, DiMaggio DA, Hotchkiss AJ, Crowley WR, Zukowska-Grojec Z (1985) Neuropeptide Y and peptide YY neuronal and endocrine systems. Peptides 6:755-768.

Pan ZZ, Williams JT (1989a) GABA- and glutamate-mediated synaptic potentials in rat dorsal raphe nucleus in vitro. J Neurophysiol 61:719-726.

Pan ZZ, Williams JT (1989b) Differential actions of cocaine and amphetamine on dorsal raphe neurons in vitro. J Pharmacol Exp Ther 251:56-62.

Pan ZZ, Colmers WF, Williams JT (1989) 5-HT mediated synaptic potentials in the dorsal raphe nucleus: interactions with excitatory amino acid and GABA neurotransmission. J Neurophysiol 62:481486.

Pernow J, Saria A, Lundberg JM (1986) Mechanisms underlying preand post-junctional effects of neuropeptide $Y$ in sympathetic vascular control. Acta Physiol Scand 126:239-249.

Saria A, Theodorsson-Norheim E, Lundberg JM (1985) Evidence for specific neuropeptide $Y$-binding sites in rat brain synaptosomes. Eur J Pharmacol 107:105-107.

Shimizu H, Bray GA (1989) Effects of neuropeptide Y on noradrenaline and serotonin metabolism in rat hypothalamus in vivo. Brain Res Bull 22:945-950.

Tatemoto K (1982) Neuropeptide Y: complete amino acid sequence of the brain peptide. Proc Natl Acad Sci USA 79:5485-5489.

Wahlestedt C, Yanaihara N, Håkanson R (1986) Evidence for preand postjunctional receptors for NPY and related peptides. Regul Pept 13:307-318.

Wahlestedt C, Grundemar L, Håkanson R, Heilig M, Shen GH, Zukowska-Grojec Z, Reis DJ (1990) Neuropeptide $Y$ receptor subtypes, $Y_{1}$ and $Y_{2}$. Ann NY Acad Sci 611:7-26.

Williams JT, Colmers WF, Pan ZZ (1988) Voltage and ligand-activated inwardly rectifying currents in dorsal raphe in vitro. J Neurosci 8:3499-3506.

Yoshimura M, Higashi H (1985) 5-Hydroxytryptamine mediates inhibitory postsynaptic potentials in rat dorsal raphe neurons. Neurosci Lett 53:67-74.

Yoshimura M, Higashi H, Nishi S (1985) Noradrenaline mediates slow excitatory synaptic potential in rat dorsal raphe neurons in vitro. Neurosci Lett 61:305-310. 